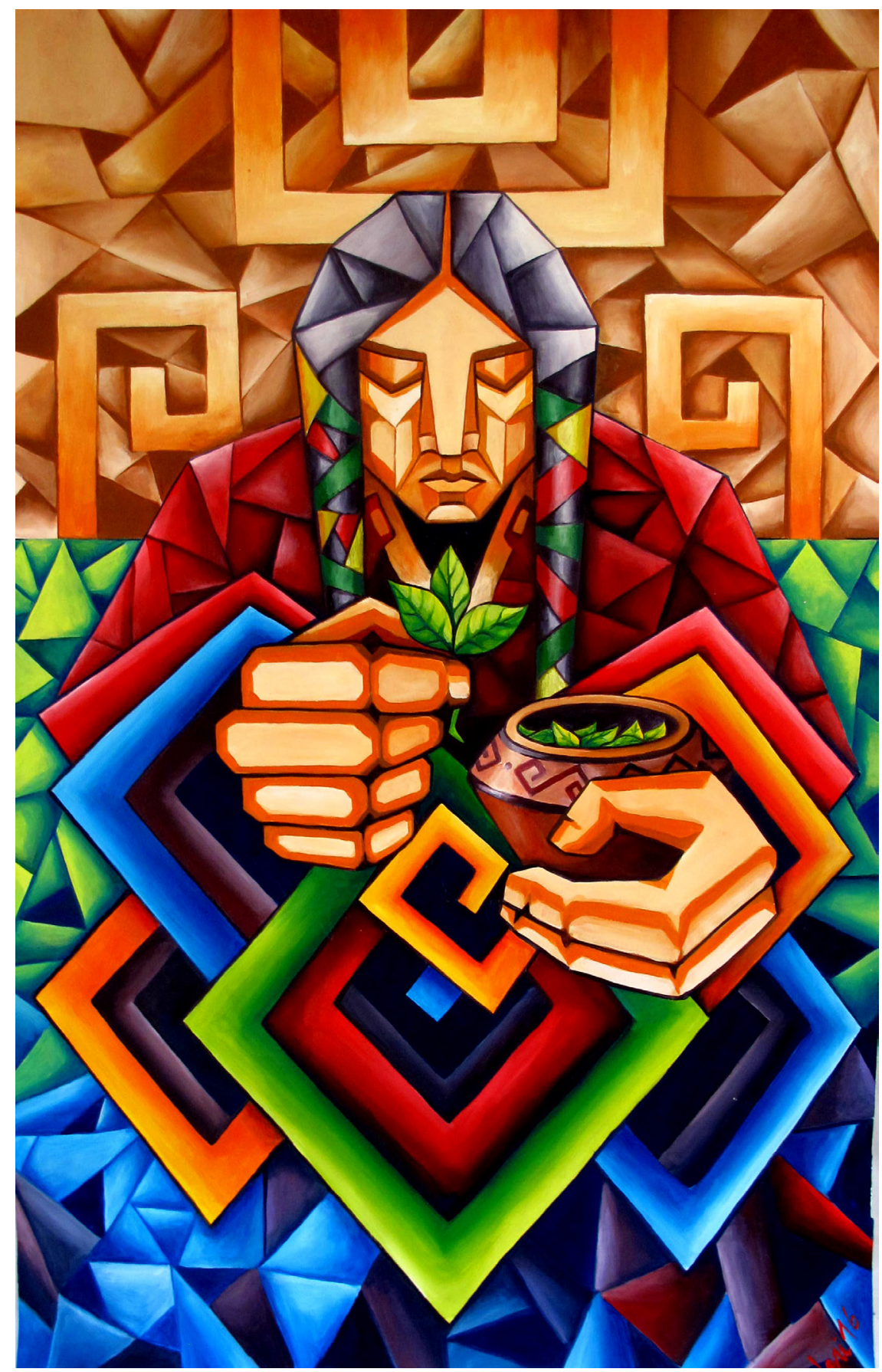

Artista: Heri Tapia 


\section{Viajes y encuentros pedagógicos como experiencias de formación de maestros ${ }^{1}$}

\author{
TRAVELS AND PEDAGOGICAL MEETINGS AS TEACHER TRAINING EXPERIENCES \\ - VIAGENS E ENCONTROS PEDAGÓGICOS COMO EXPERIÊNCIAS DE FORMAÇÃO \\ DE PROFESSORES
}

\author{
María del Pilar Unda B.2/ pilunda@gmail.com \\ Alba Nelly Gutiérrez C.3 / albanellygutierrez@hotmail.es
}

\section{Resumen}

Desde los primeros viajes y en cada uno de los seminarios de producción de saber realizados por la Expedición Pedagógica Nacional, han resultado sorprendentes las constantes referencias a la incidencia que estos han tenido en las maestras y los maestros participantes. Por ello, se quiso indagar sobre los viajes como alternativa de formación y sobre la riqueza pedagógica de las prácticas pedagógicas visitadas, a partir de los relatos elaborados por los maestros que participaron como viajeros en el marco del proyecto realizado entre el IDEP y la UPN, durante el primer semestre de 2015. Este artículo presenta los resultados del estudio.

\section{Abstract}

From the first travels, and during each of the seminars on knowledge production organized by the National Pedagogical Expedition, it has been striking to receive constant references to the impact of these travels on participating teachers. For this reason, this article aims to examine travels as an alternative training, as well as the pedagogical wealth of the teaching practices used, based on the reports prepared by the teachers who participated as travelers in the project which was carried out by the Universidad Pedagógica Nacional (UPN) in collaboration with the Instituto para la Investigación Educativa y el Desarrollo Pedagógica (IDEP) during the first half of 2015. This paper presents the study results.

\section{Resumo}

Desde as primeiras viagens e em cada um dos seminários de produção de saber realizados pela Expedição Pedagógica Nacional, foram surpreendentes as constantes referências à incidência que esses tiveram nas professoras e professores participantes. Por isso, surgiu o interesse de indagar sobre as viagens como alternativa de formação e sobre a riqueza pedagógica das práticas pedagógicas visitadas, a partir dos relatos elaborados pelos maestros que participaram como viageiros no marco do projeto realizado entre o IDEP e a UPN, no primeiro semestre de 2015. Esse artigo apresenta os resultados do estudo.

Fecha de recepción: 08 de agosto de 2015 / Fecha de aprobación: 05 de septiembre de 2015

1 Este artículo surge como uno de los resultados del proyecto Cualificación de Maestras y Maestros en Ejercicio "Intercambio de experiencias pedagógicas significativas", ejecutado a través del Convenio IDEP-UPN, durante el primer semestre de 2015.

2 Profesora e investigadora, Universidad Pedagógica Nacional. Coordinadora General Convenio IDEP-UPN.

3 Asesora Dirección del IDEP. Integrante Comité Técnico del Convenio IDEP-UPN.
Palabras clave

Formación de maestros, prácticas pedagógicas, viajes expedicionarios.

Keywords

Teacher training, pedagogical practices, expeditionary travels.

Palavras chave

Formação de professores, práticas pedagógicas, viagens expedicionárias. 


\section{Unas reflexiones iniciales}

Desde los inicios del Movimiento Pedagógico, en la década de 1980, se han adelantado en Colombia importantes controversias sobre el maestro y la pedagogía. En particular, se han formulado un conjunto de críticas a la pretensión de instrumentalizar al maestro y de convertirlo en un simple operario subordinado a propósitos, planes y programas que no consultan sus saberes, sus prácticas ni sus propuestas, ni toman en cuenta las condiciones en las que estas se realizan.

Las herramientas conceptuales aportadas por el Movimiento Pedagógico a lo largo de más de 30 años se convierten hoy en claves de lectura de primera importancia en relación con el lugar que ocupa el maestro tanto en las políticas como en los planes y los programas de formación. Este artículo, surgido de un proceso de trabajo realizado conjuntamente por el Instituto para la Investigación y el Desarrollo Pedagógico (IDEP) y la Universidad Pedagógica Nacional (UPN), pone en juego estas herramientas en la realización de viajes inspirados en la propuesta de la Expedición Pedagógica Nacional, e intenta una lectura de estos con la perspectiva de indagar por la riqueza de las prácticas que se ponen en juego y de sus aportes a la formación de maestros.

En torno a la Federación Colombiana de Educadores (FECODE), se produjo a finales de los años setenta del siglo xx y durante la década de 1980 un conjunto de formulaciones sobre el enfoque de la "tecnología educativa", presente por entonces en las políticas educativas. El empeño en construir universales y de fundamentar "científicamente" el proceso educativo, así como la perspectiva taylorista de la Reforma Curricular de 1978, según la cual unos piensan la educación y otros - en este caso, los maestros - la llevan a cabo y se convierten en simples ejecutores, fue objeto de amplias discusiones; en especial, a partir de los trabajos desarrollados por el grupo de investigación de la Universidad Nacional (UN) liderado por el profesor Carlo Federicci (Federicci et al., 1984).

Otro tema central en el Movimiento Pedagógico ha sido el reconocimiento de la pedagogía como el saber propio de los maestros, y a partir del cual es posible para ellos distanciarse de las prescripciones provenientes de otras prácticas disciplinares, políticas o culturales, y así pensarse a sí mismos en relación con lo que hacen y con su propia experiencia. Las nociones de práctica pedagógica y de saber pedagógico "aportan para problematizar la marginalización del estatuto del saber de los maestros y la condición subalterna a la que se han visto sometidos. Estas nociones proporcionan una base conceptual desde la que es posible hacer intercambios con otros saberes, sin que dicho saber pierda su especificidad ni su autonomía." (Zuluaga, 1999, p. 3)

La envergadura de planteamientos como estos, sobre los cuales aún se sigue trabajando, ha sido resaltada por Abel Rodríguez, en su artículo "El Movimiento Pedagógico: un encuentro de los maestros con la pedagogía" (2002). En la misma vía, más recientemente, Alberto Echeverry (2009) propone el concepto de campo conceptual de la pedagogía. Con base en este concepto, se acentúa el distanciamiento con los enfoques "que no ven en la pedagogía potencia para convertirse en un campo de producción conceptual" (p. 4) y se replantea el lugar que el maestro ha ocupado en la división social de los saberes.

La participación del sindicato de educadores y de los grupos de investigación de las universidades en el Movimiento Pedagógico ha sido ampliamente documentada. El liderazgo y la capacidad de convocatoria de FECODE en la década de 1980, se convirtió en un verdadero acontecimiento: “(...) Que un sindicato entrara a ocuparse de un asunto propio de la academia y la cultura, como lo es el saber, reservado históricamente a intelectuales e investigadores, [constituye] una auténtica revolución tanto en el mundo sindical, como en el cultural." (Rodríguez, 2002, p. 18)

Menos reseñada en los trabajos sobre la trayectoria del Movimiento Pedagógico ha sido la participación de las maestras y los maestros que nutrieron y le dieron vida desde su inicio. Fueron grupos de maestros "que ya reflexionaban sus prácticas" los que "alertaron al sindicato, sobre las dimensiones de la política de la reforma educativa del 78" (Rodríguez, 2002, p. 32). Son ellas y ellos, precisamente, quienes le han dado continuidad y quienes no han dejado de convocarse y de movilizarse, y han resistido así a la sumisión y a la obediencia que se les pretende imponer a través de los mecanismos de 
control y de vigilancia promovidos en las políticas y en los planes educativos de distinto orden, tanto en el ámbito local, como en el nacional y el internacional.

Estas acciones de resistencia han tomado como formas de organización expresiones plurales como las redes, las agrupaciones y los colectivos pedagógicos. Resultan de maestras y maestros que ven en el encuentro con otros un modo muy vital de enfrentar las preguntas, las dificultades y los desafíos que se plantean en relación con sus prácticas y con pensarse a sí mismos teniendo en cuenta sus trayectos, sus saberes, sus deseos. Tenemos hoy un movimiento de maestros, y de otros intelectuales de la educación, que construye nuevos escenarios de trabajo colectivo en el cruce, en la intersección, de unos puntos de ruptura con respecto a los modos convencionales de pensar el tema del maestro, que, a la vez, le apuntan a pensar de otro modo su formación.

Algunas universidades públicas han adelantado proyectos de redes como alternativa a los procesos institucionalizados de formación de maestros en ejercicio. Así ha ocurrido, por ejemplo, en la Universidad Nacional, en la Universidad del Valle y en la Universidad Pedagógica Nacional. Esta última, desde mediados de la década de 1990, a través del proyecto Red de Cualificación de Educadores en Ejercicio (RED CEE), planteó una ruptura radical con los modelos ligados al concepto de "capacitación", dominantes en América Latina. Propuso, en cambio, la creación de escenarios de formación en el encuentro y el intercambio, en el reconocimiento y la valoración de los saberes y de las prácticas de las maestras y los maestros.

Con esta perspectiva, Red no es simplemente un nuevo nombre para actualizar viejas formas organizativas. Se refiere, en cambio, a ciertos tipos de conexiones entre maestros que rompen con la insularidad que les plantean las perspectivas eficientistas de la administración del sistema escolar. Maestros que se deciden al encuentro, al intercambio y al trabajo conjunto, ensayando así otros diagramas de circulación de saberes, nuevas relaciones de poder que se distancian de la dependencia y la sumisión, de las relaciones jerárquicas, autoritarias y de control (Martínez \& Unda, 1995).
Es en los encuentros entre las redes que ya existían en distintas regiones ${ }^{4}$ donde se da vida y se nutre, a finales de los años 90, la propuesta de Expedición Pedagógica Nacional, elaborada desde la UPN y presentada ante las instancias que contribuyeron a su financiación y su desarrollo $^{5}$. Cada red tenía la capacidad de hacer un mapeo de la heterogeneidad de las regiones en las cuales tenía presencia, lo que resultó clave para la construcción de rutas que dieran cuenta de la diversidad de formas de hacer escuela, lo cual fue desde el comienzo una de las preguntas de la Expedición. Por otra parte, cada una de ellas tenía una trayectoria y una experiencia de trabajo en colectivo, indispensables para la conformación de grupos de maestros viajeros y para la movilización y la programación de los encuentros en los colegios anfitriones de quienes los visitaban. Fueron, pues, las redes las encargadas de constituir los equipos organizativos y movilizadores de la Expedición invitando a las instituciones y las organizaciones educativas de sus regiones a pensar, diseñar y realizar conjuntamente la respectiva propuesta expedicionaria, en un trabajo coordinado en todo el país, que aún hoy se mueve en un juego entre distintos planos: el local, el regional y el nacional.

Precisamente, el concepto geopedagogía surgió en el desarrollo de los encuentros expedicionarios y fue recogido en el proceso de evaluación de la Expedición en el documento Expedición a la Expedición, realizado por Gabriela Messina y Humberto Quiceno (2002), a partir de sus visitas a los equipos expedicionarios en pleno proceso de producción de saber sobre las primeras rutas realizadas. El concepto geopedagogía se refiere a las conexiones entre las prácticas pedagógicas de los maestros, la vida de las poblaciones, y las condiciones históricas y culturales de los territorios en los cuales trabajan. Más allá de ello, expresa los interrogantes, las problematizaciones y las propuestas que surgen en esa relación.

4 Ver: Enredes 97, Hacia nuevas formas de expresión y trabajo pedagógico. Revista Nodos y Nudos 4, publicado en junio de 1998.

5 El Fondo MEN-ICETEX aportó un presupuesto a modo de "capital semilla" para la puesta en marcha de la Expedición y la realización de los viajes que se llevaron a cabo en 1999 y 2000 en cuatro regiones del país. A este "capital semilla" se unieron recursos económicos, profesionales y materiales de otras organizaciones no gubernamentales, nacionales y locales, así como de organizaciones de maestros, e, incluso, aportes de los propios educadores participantes. Posteriormente se desarrollaron otros viajes y expediciones con aportes de la Fundación FORD, de la Universidad Pedagógica, de la Fundación Restrepo Barco y de otras organizaciones. 
Pensar al maestro como un intelectual, reconocer que tiene un saber con una historicidad y un estatuto propio, y asumir el carácter público de la acción del maestro, en la medida en que esta se entreteje y se relaciona directamente con la cultura, son aportes de esta fructífera discusión. Esos elementos se convierten en importantes herramientas de orden conceptual para hacer una aproximación al tema de la formación de maestros y a la comprensión de las prácticas y las formas de ser maestro. Surgen preguntas por los posicionamientos de los programas institucionales: pregrados, posgrados y aquellos de formación de maestros en ejercicio. De la misma manera, surgen reflexiones acerca de sus prácticas y sobre sus aportes respecto a los modos de pensar al maestro. Por otra parte, son reiteradas y muy entusiastas las afirmaciones de los maestros sobre el carácter formativo que tienen las distintas iniciativas de trabajo colectivo. ¿En qué consiste, cómo se produce y cómo se vive la formación en estas otras prácticas que reconocen el carácter del maestro como sujeto, en relación directa con sus propios saberes y sus prácticas?

\section{Los viajes como formación}

La iniciativa conjunta del Instituto para la Investigación Educativa y el Desarrollo Pedagógico, IDEP y de la Universidad Pedagógica Nacional, denominada Proyecto Intercambio Académico de Docentes y/o Directivos Docentes con Experiencias Significativas (llevada a cabo en el primer semestre de 2015) se preguntó, en particular, por la formación de maestros. Se realizó con 59 maestras y maestros de distintos colegios de Bogotá, quienes realizaron viajes para el encuentro y el intercambio con las prácticas y los maestros de diferentes regiones, con la perspectiva de la Expedición Pedagógica Nacional.

\section{Preparación y realización de los viajes}

La realización de estos viajes 6 no ha sido, pues, un proceso aislado. Al contrario, se ha inspirado en el acumulado del Movimiento Pedagógico: en la problematización sobre el ser maestro, sobre su saber, en el interés por comprender su relación con las condiciones

6 Este artículo se refiere a los viajes realizados en el 2015-I, sin embargo, durante el 2015-II se pusieron en marcha otros viajes. y las culturas diversas de nuestro territorio, así como en el reconocimiento del carácter ético y político de sus prácticas. Los viajes son una invitación a hacerse parte de esa historia, a experimentar y encontrar nuevas rutas y propuestas de trabajo conjunto que contribuyan a la construcción de nuevas miradas sobre la escuela. Se trata de un ejercicio de producción de saber que pone en juego las vivencias, las perspectivas y las propuestas de los maestros que participan en él.

Ahora bien, las dos instituciones que propiciaron el proyecto objeto de este artículo cuentan con una importante trayectoria en la búsqueda y la experimentación de propuestas de formación de maestros, a través de la creación de alternativas y escenarios que rompen con los esquemas fundamentados en la capacitación y en la actualización. Tanto el IDEP como la UPN han ensayado procesos de formación que dan importancia a la práctica, al saber, al deseo y a la potencia del maestro, a sus modos de pensarse y de inventarse a sí mismo. Por eso, para el proyecto la pregunta por la formación a través de los viajes es central: ¿cuáles son los aportes de los viajes y los encuentros pedagógicos, para quienes en ellos participan?

Como parte de su estrategia de cualificación docente, el IDEP realiza un trabajo de acompañamiento in situ que se orienta a desarrollar procesos de sistematización de las iniciativas pedagógicas de maestros, maestras y directivos de diferentes colegios oficiales de Bogotá. Se entiende la sistematización como metodología de investigación y de producción de saber que permite a quienes participan entender y conceptualizar sus propias prácticas, lo cual se traduce también en un exigente ejercicio escritural.

Durante 2014, la estrategia de acompañamiento se concretó en un proceso con la participación de 60 maestros y directivos docentes de 16 colegios de Bogotá. Al terminar satisfactoriamente este proceso, el IDEP pensó en la realización de viajes y oportunidades de interlocución con maestros de otras regiones. La idea surgió, entre otras causas, de la positiva experiencia de una visita realizada inicialmente al Colegio Puente Amarillo, en el departamento del Meta7 ${ }^{7}$ Los viajes se asumieron como posibilidad de crear espacios para

\footnotetext{
7 Visita organizada por el IDEP al finalizar el programa de "formación in situ" con los maestros que participaron en la sistematización de sus prácticas.
} 
compartir las producciones de los maestros con pares, exponerse, ser escuchados y conversar con otros; todo ello en la perspectiva de continuar redefiniendo el papel del maestro, visto como sujeto de su propia formación y de la creación de nuevos diagramas para la circulación y el intercambio de saberes, prácticas y propuestas.

Tanto para identificar y seleccionar los lugares y prácticas por visitar, como para conformar los grupos de viajeros, se tomaron como referentes los temas siguientes, en torno a los cuales adelantaban sus trabajos los maestros viajeros: (a) Ruralidad, (b) Lenguajes y expresión, (c) Educación inclusiva, (d) Infancia, (e) Ciencia y Tecnología y (f) Compromiso con el cambio climático.

Durante la realización del proyecto se contó con los aportes de maestras, directivas e integrantes de instituciones educativas ${ }^{8}$, quienes asumieron la responsabilidad de identificar las propuestas de interés en sus respectivas regiones, le dieron vida a la propuesta, contribuyeron a garantizar las mejores condiciones para los encuentros y sirvieron de guía y de acompañamiento en cada lugar.

Finalmente, un total de 50 maestras, maestros y directivos $^{9}$ —de ellos, 45 provenientes de los 16 colegios oficiales de Bogotá con los que había trabajado el IDEP, en un proyecto de sistematización de prácticas, y 14 del IPN - participaron en un proceso de preparación como expedicionarios y en la realización de los viajes a las prácticas identificadas: Marco Fidel Suárez (BarranquiIla), ACERG (El Dovio, Valle del Cauca), IDEBIC (Florida, Valle del Cauca), José Acevedo y Gómez y Alfredo Cock Arango (Medellín) y Puerto Inírida (Guainía). En todos los casos, la programación incluyó actividades orientadas al reconocimiento cultural, social y geográfico de los territorios.

8 Nos referimos a Astrid Coronado en Barranquilla, supervisora e integrante del equipo del movimiento expedicionario del Caribe; a Esperanza Montaño, en el Valle, supervisora y coordinadora de la Expedición del Suroccidente Colombiano en su primera fase; a Sandra Ramos, en Puerto Inírida, coordinadora de la Unidad de Necesidades Educativas Especiales; a Lía Córdoba, maestra e integrante del Proyecto MOVA de Medellín; a Nora Villa, maestra e integrante del equipo expedicionario de Medellín, y a Pilar Rubio, quien también hizo parte del equipo de la Expedición en Medellín, durante su primer momento.
¿En qué consistió la preparación de los viajeros?

La preparación de los maestros en la perspectiva expedicionaria supone una aproximación a determinadas herramientas conceptuales, como la mirada, el viaje y la producción colectiva de saber. De la misma manera, significa asumir posibles instrumentos para registrar y contar lo que se observa y se vive durante los viajes.

La mirada hace referencia a la diversidad y la riqueza pedagógicas como supuestos que se convierten, a la vez, en una apuesta, en una ruptura con las pretensiones homogenizantes de las políticas educativas de este tiempo y con algunos sesgos que buscan convertir unas prácticas en "modelos" para ser replicados por otros. La mirada implica un distanciamiento de los enfoques diagnósticos que ven al maestro como sujeto de carencias y limitaciones, una ruptura con los enfoques que lo convierten en objeto para ser "capacitado" por otros.

El viaje, como un "caminar por los territorios", es, a la vez, un recorrido físico y un desplazamiento en el orden del pensamiento. Es otro modo de la formación, en la que los maestros se enfrentan a lo inesperado, se dejan sorprender, reconocen y valoran los saberes, las prácticas y las propuestas de otros maestros en las condiciones sociales y culturales en las cuales emergen sus prácticas. No es un viaje turístico o de descanso: plantea unas exigencias, entraña dificultades, incertidumbres. Por ello, la formación no antecede a los viajes, sino que se continúa durante ellos.

El ejercicio de producción colectiva hace de los viajes una posibilidad de producir saber sobre las escuelas y los maestros a partir de los registros, de las sensibilidades y de las emociones producidas en los maestros viajeros. Es quizá, uno de los momentos más exigentes y, a la vez, uno de los acontecimientos más apasionantes del proceso expedicionario. La exigencia de este ejercicio de producción requiere tiempos y permanencias que muchas veces superan los límites de un proyecto como el constituido a través de esta iniciativa. Sin embargo, es también un reto que presupone la conformación de una "caja de herramientas" en la que se despliegan diversos instrumentos para el registro y la escritura de los viajes: bitácoras, mapas, cuadernos de notas, fotografías, historias de vida, entrevistas, relatos (Expedición Pedagógica Nacional, 2001).

9 De este total, había 43 maestras y 16 maestros. 
¿Qué aportan los viajes a la formación de maestros? La formación en las voces y las experiencias de los maestros viajeros

El trabajo de preparación y realización de los viajes dentro del marco del convenio UPN-IDEP estuvo acompañado de dos preguntas: ¿Qué aportan los viajes expedicionarios a la formación de maestros? ¿Qué les ocurre a los maestros y a los directivos docentes a propósito de los viajes?

El viaje expedicionario, como lo hemos entendido, es un viaje de cada maestro al interior de sí mismo. No ocurre sin una transformación. Sin embargo, esta es impredecible: el viajero va cargado de numerosas y variadas expectativas y preguntas, pero no puede prever qué le ocurrirá durante el viaje. Esto le da un carácter, lo diferencia de otros programas de formación, se asemeja más a una aventura, en los términos de Quiceno (2001): “(...) la aventura que conoce paso a paso lo que sucederá pierde sentido porque se convierte en un programa que se debe cumplir y se desprecia la preciada cita con la contingencia" (p. 72).

El viaje expedicionario, como ruta de formación de maestros, se diferencia de los "programas" de capacitación, de actualización o de formación posgradual, pues rompe con el esquema según el cual unos enseñan a otros determinados contenidos de conocimiento, o los instruyen en particulares formas de actuación. Esta es su primera y más importante característica: no son otros quienes forman al maestro, sino que es el maestro quien se forma a sí mismo. Esta ruta de formación no se piensa como "programa", no se propone identificar de antemano cuáles van a ser sus resultados, no hay punto de llegada. No se trata de alcanzar unos determinados conocimientos o "aprendizajes"; tampoco, de obtener un título, un certificado o un escalafón. La pregunta es otra: es sobre cómo pasan estos viajes por el sujeto, qué quiebres producen.

La formación de maestros en esta propuesta no se refiere estrictamente al hecho de viajar de un lugar a otro, a tener la oportunidad de recorrer y visitar distintos sitios y encontrarse con otros maestros, con otras instituciones educativas y con las prácticas que en ellas se realizan. Es aquí donde la noción de experiencia, retomando los trabajos de Dewey y de Larrosa, se con- vierte en una clave importante para la lectura. Para que el viaje se convierta en formación es necesario que este, o algo de lo que suceda durante este, se convierta en experiencia; es decir, se requiere que pase por el sujeto. En palabras de Foucault, "una experiencia es algo de lo cual sales cambiado" (entrevista con D. Trombadori, citada por Jay, 2003, p. 138).

La pregunta está abierta: ¿qué se moviliza y qué le ocurre al maestro durante el viaje y a partir de este?

\section{Los relatos de los viajeros}

Este estudio se detiene en la exploración de los viajes como experiencia de formación, tal como esta es narrada en los "relatos viajeros". De este modo, la formación, como aquí la entendemos, es reconocida, contada y escrita.

Escritura como ensayo, como experimentación, que da cabida a los sentimientos, a las emociones, a las preguntas, a las ideas; escritura que se distancia de las pretensiones de objetividad, de las formas de escritura propias de los informes administrativos y de los modelos académicos. Sin temor a ponerse en cuestión por "falta de rigurosidad" o por no seguir un determinado formato, los maestros se autorizan a sí mismos para hablar, se asumen desde su propio testimonio, desde sus inquietudes, desde sus apuestas y sus sueños.

La aproximación a los viajes como experiencia de formación se realizó a través de una lectura detenida de cada relato y el uso de herramientas de sistematización de los documentos. La información se organizó en torno a las siguientes temáticas identificadas como centrales en los escritos: (a) El viaje, incluye las referencias a los viajes, a la manera como estos fueron asumidos y pensados por los maestros viajeros, a las expectativas y las preguntas que suscitaron; (b) El encuentro con otros maestros y formas de hacer escuela, es el tema al que más se dedican los relatos, a todo lo que sorprende y se destaca de las prácticas visitadas en cada lugar; (c) La experiencia, donde se recogen las múltiples expresiones de extrañamiento, las fracturas, la formulación de nuevas preguntas, las contrastaciones con los propios modos de pensar, de ver el mundo, de verse a sí mismos. 
El viaje

"Nuestro destino nunca es un lugar, sino una nueva forma de ver las cosas"

Esta cita de Henry Miller, presentada por Sergio, maestro del IPN, en su relato de viaje, como lo "más acertado para describir lo acontecido en la Expedición Pedagógica"10, permite ver el carácter del viaje: una disposición para ver de otra manera y dejarse sorprender, permear, afectar, abrirse a las prácticas, a los paisajes, a las culturas y a los territorios recorridos. Es la provocación que hizo hace unos años Fernando González con la figura del "viajero pensador" en su Viaje a Pie (1929): un modo de caminar, una invitación al pensamiento. Abrir "miradores y salidas al mundo", diría este filósofo de Otraparte.

A la diferenciación entre distintos modos de viajar también se refiere Carlos $\mathrm{H}$., cuando afirma: "no es lo mismo cuando se viaja en la familia como turista..."11. Es un viaje diferente. Esto es lo que permite que algunos hablen del inicio de su viaje antes de salir hacia otros lugares, desde el encuentro inicial de presentación del proyecto ${ }^{12}$, con el reconocimiento entre los maestros de Bogotá de diferentes colegios que irían a un mismo lugar. No estaba previsto, pero llama la atención cómo en ese mismo momento algunos iniciaron el intercambio y la construcción de propuestas conjuntas: "Durante la preparación de nuestra expedición, después de programar los itinerarios del grupo fue para nosotros una gran alegría ya que desde ese momento empezamos a interactuar con los compañeros", dice Carlos $\mathrm{H}$.

Desde las primeras intervenciones con otros docentes, que hablaban de sus logros y alcances en colegios de Bogotá y de los cuales no tenía conocimiento, sentí la necesidad de hablar sin ningún temor sobre quién soy gracias a mi labor como docente"13.

Al llegar el momento del viaje ya conocía el grupo de maestros con el que iba a compartir en esta

10 Sergio Alfonso, viajero, Colegio Instituto Pedagógico Nacional (IPN).

11 Carlos Humberto Motta, Colegio Guillermo León Valencia.

12 Encuentro inicial de presentación del proyecto, en marzo de 2015.

13 Marcia Alejandra Ramos, viajera IPN gran expedición; profesores con mucho interés en sus propios proyectos dentro de su colegio. Como grupo que íbamos a este lugar elaboramos un trabajo manual donde se recopiló un pequeño informe de los proyectos que cada uno trabaja en su colegio, dice Rocío ${ }^{14}$.

En ese momento comenzó el viaje, un viaje que deja ver la fuerza que tiene el intercambio entre maestros, las emociones que despierta, lo sorprendente que resulta el reconocimiento de otros maestros, los efectos que tiene todo ello en la valoración y la afirmación de sí mismos.

El taller de preparación de viajeros, denominado Un viaje a la Expedición Pedagógica Nacional, contribuyó a aumentar el interés y las expectativas sobre los viajes. Así mismo, permitió la definición del carácter pedagógico de estos:

Contamos con un excelente taller descriptivo y práctico llevado a cabo en el Instituto Pedagógico... que nos provocó mentalmente cuál sería la visión pedagógica que tendríamos como visitantes $y$, la oportunidad de interactuar con pares en diferentes contextos para así nutrirnos de las distintas realidades sociales en las cuales se desempeñan nuestros colegas. De igual manera una invitación a prepararnos física, cultural y mentalmente para viajar a una región que estaba muy lejana y que no conocíamos y debíamos aprovechar al máximo para enriquecernos como docentes y como personas, dice María C.15

"Cuando asistí a los talleres de preparación del viaje, aclaré muchas dudas y aumentaron mis expectativas de realizar el viaje", afirma Rocío.

“¿Qué encontraría? ¿Con qué personas compartiría? ¿Me serviría esta experiencia para mejorar mi práctica?"16. Estas preguntas que se hacía Carolay antes de iniciar su viaje, dejan ver el carácter pedagógico y el interés en la incidencia que este podría tener sobre su propia práctica. En la misma dirección, encontramos las palabras de Hilda: "Nuestra aventura comienza con el inquietante

14 Rocío Calderón, viajera IPN.

15 María Cristina Modesto, viajera Colegio Restrepo Millán.

16 Carolay Abella, Colegio Quiba Alta. 
mundo de la curiosidad por aprender de otros"17. Carlos H., por su parte, dice: “(...) realizar un recorrido alimenta al docente de expectativas que le ayuda a la labor diaria", así como para Nelcy, Blanca y Yenny "continuamos sumergiéndonos en la profundidad del conocimiento al hacer un viaje más allá de la tiza y el tablero donde el maestro se siente llamado, seducido y convocado por su quehacer pedagógico"18. Estos testimonios dejan ver a unos maestros entusiastas y apasionados con su quehacer, muy distintos de los que describen los discursos del "malestar docente", dispuestos al encuentro con otros, deseosos de pensar y de actuar sobre sus propias prácticas.

Por otro lado, en relación con el uso de los instrumentos de registro de la "caja de herramientas" expedicionaria, encontramos esta referencia:

Iba recordando las indicaciones que me dieron para hacer de ese momento perdurable en mi vida y mi labor. Repasé si llevaba todo en la maleta: La libreta pedagógica, lista; la cámara fotográfica, lista; la tableta, lista; la USB con la presentación de mi colegio, lista; el recuerdo para nuestros anfitriones, listo y lo más importante las expectativas y las ganas de aprender de lo que otros hacen, estaban listas desde el momento en que supe que emprendería este viaje. (Carolay)

Desde el inicio, se contó con las expectativas, las ganas, el entusiasmo y la decisión de vencer las dificultades, como lo señala Sonia:

(...) muy temprano se estuvo en el aeropuerto. En cada rostro de nuestros compañeros viajeros se irradiaba una gran alegría y felicidad a pesar de que se dejaba en la ciudad de Bogotá a nuestros padres, esposos, esposas o hijos al cuidado de alguien; algunos de ellos con algunos problemas de salud delicados pero que no fueron obstáculos para esta gran aventura ${ }^{19}$.

17 Hilda Ruby Silva, viajera Colegio Porfirio Barba Jacob.

18 Nelcy Rubiela Carrillo, Blanca Arely Sierra, Yenny Constanza Marentes y Diana Constanza Torres (relato conjunto), viajeras Colegio Santa Marta.

19 Sonia C. Espinosa, viajera Colegio Rodolfo Llinás.

\section{El encuentro con otros maestros y formas de} hacer escuela

Como era de esperarse, es sobre el encuentro con cada una de las escuelas visitadas, con los rectores, con los maestros y con las poblaciones en las que se tuvo la oportunidad de interactuar durante los viajes, en lo que se centraron principalmente los relatos, sobre lo que llevó a las mayores exclamaciones de extrañamiento, de entusiasmo, y valoración de lo diferente de lo ya sabido. Es en este énfasis en las particularidades de cada práctica (su relación con los territorios, sus aportes y su riqueza) donde se puede apreciar mejor la incidencia de lo que podríamos denominar "experiencia de los viajes". Algunos de los relatos se tornan más descriptivos para hacer ver eso que se quiere destacar de cada práctica; en otros es posible encontrar la intensidad de la vivencia de lo "otro" y cómo se devuelve sobre el mismo maestro e interroga sus propios modos de pensar, de abordar la escuela y de pensar sus propias prácticas.

Sorprende la manera como estos maestros, estas escuelas, contribuyen al pensamiento sobre la pedagogía y sobre la formación de maestros en Colombia. Sus relatos abren otras perspectivas que pueden contribuir a la definición de unas políticas educativas que tengan en cuenta su potencia y sus aportes en relación con unos territorios que, definitivamente, no pueden ser leídos con perspectivas sobre la "calidad" de la educación basadas en pruebas estandarizadas.

A continuación, se presenta cada una de las prácticas visitadas en las regiones, así como su valoración y los aportes a la formación, leídos a través de los relatos viajeros.

Una escuela que incorpora y se vincula al Carnaval aportando su actividad académica y artística: el Colegio Marco F. Suárez y la Escuela Normal Superior La Hacienda (Barranquilla)

En el Colegio Marco Fidel Suárez y en la Escuela Normal Superior La Hacienda, el Carnaval de Barranquilla se ha convertido en un motivo y en una inspiración que lleva a vincular las prácticas pedagógicas enlazando saberes, sentires y emociones a su más valioso patrimonio cultural, en una conexión especial con el pueblo, con su historia, con su identidad. Los maestros realizan y orientan propuestas investigativas con sus 
estudiantes sobre temas relacionados con el Caribe colombiano, sus raíces, su historia y sus tradiciones, que luego convierten en obras artísticas, como aporte al Carnaval; en relación con ello, trabajan la oralidad, la escritura, la lectura, las matemáticas, las ciencias y distintas expresiones como música, danza, teatro, pintura y literatura. Su insistencia en entender el Carnaval como patrimonio cultural marca una clara diferenciación con las perspectivas que lo reducen a lo folclórico o a un producto de consumo en la lógica de mercado.

Carlos H. comparte las preguntas que lo acompañaban antes de su llegada a este colegio:

Nuestra expectativa de conocer una experiencia pedagógica a nivel artístico donde su desarrollo metodológico se basa en la música, danza teatro, oralidad y sus fundamentos de aprendizaje es el Carnaval de Barranquilla, fue una expectativa que fue creciendo durante nuestra preparación del viaje con interrogantes grandes como: ¿cuál será la forma de integrar una fiesta de carácter popular a un ambiente de aprendizaje?

Los viajeros destacaron la magnitud de este trabajo y la vitalidad de los maestros que lo realizan; manifestaron insistentemente eso de quien lo vive es quien lo goza haciendo suyas los palabras de los barranquilleros respecto al Carnaval, para aplicarlo a la oportunidad de haber vivido directamente esta propuesta pedagógica, como lo expresan Isabel y Liliana.20 Ellas se muestran sorprendidas con ese "intercambio lleno de vida... descubrir la pasión con que sus protagonistas lo expresan y lo narran, lo sienten, lo interiorizan, lo viven, lo celebran".

El maestro Álvaro, nombrado "Rey Momo" del Carnaval del 201421, es quien lidera la propuesta: "él hizo un clic en mi vida como maestra", dice Angélica ${ }^{22}$, por su modo de ser maestro, por su carácter como "símbolo de la tradición que se extiende a los rituales ancestrales de África y el Caribe" y por el modo como los marcó durante el viaje: "un auténtico pedagogo que nos enseña a todos a ser mejores maestros, y ante todo

20 Isabel Flórez y Liliana M. Herrera, viajeras IPN, Taller de Producción, 30 de mayo de 2015.

21 Maestro Álvaro Bustillo, Colegio Marco F. Suárez.

22 Angélica Rodríguez, viajera Colegio Francisco de Paula Santander. maestros que comunican la alegría de vivir (...)". Así mismo, se encuentran referencias de reconocimiento al maestro Tibaldo por el trabajo realizado en el colegio que "aporta vistosas y coloridas pinturas" al Carnaval23.

Así lo expresa Guillermo:

El maestro es todo un personaje, Rey Momo en el Festival del año pasado, desempeñó su papel con lujo de detalles, marcando diferencias porque presentó un contexto de la fiesta desde la apreciación académica y presentando sugerencias que fueron valoradas y puestas en práctica, con el resultado tangible de subir el nivel de la participación de las instituciones y los aportes al evento. Entonces, uno cambia de parecer respecto del evento, de mera fiesta popular a un evento cultural complejo, con raíces, historia, significados y patrones figurativos en los colores, los atuendos, la planigrafía de las comparsas y los espacios en que se desarrolla. ${ }^{24}$

Durante esta visita tuvieron la oportunidad de conocer el trabajo del maestro Renny25, de la Escuela Normal Superior La Hacienda, quien con su poderosa voz enseña a cantar letanías que aportan canto, críticas y burlas al Carnaval:

Conocer el lenguaje literario de las letanías expuestas por el maestro y cómo lo integran al currículo dándole un gozo y un disfrute, además del aprendizaje diario en la escuela llevado al carnaval a vivenciar la fiesta y hacer parte de la misma. (Carlos $\mathrm{H}$.)

Una escuela que le arrebata las niñas y los niños a la guerra y combate la destrucción de la naturaleza: ACERG (EI Dovio, Valle del Cauca)

Entender esta propuesta, impulsada desde hace 17 años por una joven maestra recién graduada de una Escuela Normal, ante la forma como la violencia afectaba principalmente a las mujeres y a las niñas, pasa por situarla en un territorio de cerca de 20.000 hectáreas que conforman el Cañón de Garrapatas. Este es uno de los pulmones naturales del país, situado

\footnotetext{
23 Maestro Tibaldo Rodríguez, Colegio Marco F. Suárez.

24 Guillermo León Carrillo, viajero Colegio Guillermo León Valencia.

25 Maestro Renny Padilla, Escuela Normal Superior La Hacienda, Barranquilla.
} 
en los límites entre los departamentos del Valle y del Chocó, y cuya tranquilidad fue arrasada por el terror de grupos armados - "paras", guerrilla, "Machos" y "Rastrojos" — que se disputaban el control territorial y produjeron desplazamientos, desapariciones y muertes, hicieron cambiar los cultivos tradicionales por coca y convirtieron "las pequeñas parcelas de los campesinos en ostentosos feudos que alimentan el apetito cocalero de los narcos que nutren esa guerra" (La Maldición del Cañón de Garrapatas, 2014).

Dentro de este marco, y con la determinación de esta maestra y del equipo de maestros que la acompaña, se definen los dos énfasis del proyecto educativo que atraviesan toda la propuesta pedagógica — agroambiental y problemática social-, con los alcances y las dimensiones que señala Carmen Alicia en su relato:

Esta escuela, en realidad, es un complejo educativo de tipo rural, constituido de 23 centros educativos distribuidos en sendas veredas del municipio y un Hogar Juvenil Campesino. En la vereda la Hondura se encuentra el colegio donde se ofrece la educación básica y media, la cual atiende la población de jóvenes internos en el hogar quienes vienen a su vez, de las otras escuelas del complejo donde se ofrece la educación básica primaria; de esta forma, se asegura el cubrimiento de toda la población rural y se garantiza la culminación del proceso educativo (...) Esta estructura tan compleja y particular, es el resultado de más de 26 años de trabajo colectivo que inicia en el compromiso de una joven maestra - Adriana Abadía- y el tejido social que poco a poco fortaleció con los hilos de vida de los padres de familia, los estudiantes, los ex alumnos, los compañeros docentes y el paisaje. Una escuela "tomada" ... empoderada por lo femenino, con un claro sentido de género donde los principios de la solidaridad, lo comunitario y lo afectivo lograron impulsar la construcción de las escuelas, la gestión de los recursos, los trámites legales y el sostenimiento de los niños y de los proyectos pedagógicos emprendidos, a través de la conformación de figuras productivas de carácter comunal... y la constitución de una organización ambiental no gubernamental (ONG) (...) Es así, que esta escuela sobrevive al profundo conflicto social que la rodea, logra mantenerse en pie y aún más, fortalecerse en medio de la guerra narcoterrorista que llevó al Dovio a ser el municipio más violento del país. Bajo las sombras del trabajo diario, logró arrebatarle a esta guerra muchos niños, pero sobre todo logró atesorar la esperanza de un mundo mejor (...).

Los viajeros resaltan el carisma, así como la capacidad de emprendimiento y de lucha, de la rectora, quien, después de recorrer las veredas visitando a cada familia para conocer las problemáticas de la región, decide levantar la escuela y liderar, junto con los maestros, los campesinos y las madres y padres de familia esta gran propuesta:

A tal punto que logran armar proyectos de un impacto tan importante por la circulación de afectos, la ampliación de libertades y capacidades, la reducción de segregación en un proceso de construcción colectiva (...) Dedican mucho tiempo de su vida al servicio de la educación, que con su liderazgo, vocación y entrega luchan por sacar adelante, como lo destaca Hilda R.

En los relatos se puede ver lo sorprendente que resultan, en las condiciones más adversas, la vitalidad y la fuerza de la escuela, de sus maestros y de los habitantes, como observa Carmen A. cuando se refiere al arraigo territorial y a las formas de resistencia "que les ha permitido permanecer y quedarse, que los invita a vivir de nuevo juntos y de forma solidaria", así como a reconstruir su territorio y "legalizar reservas forestales campesinas como formas de resistencia".

El encuentro se centró en el aspecto ambiental, pues era este el eje temático de interés de los maestros viajeros. Hilda Ruby resalta los aspectos centrales del trabajo educativo y pedagógico que allí se adelanta:

(...) buscan enseñar a sus jóvenes estudiantes la siembra responsable, con la reutilización de material orgánico para la formación del compost, formación de una huerta, el cuido de marranos, conejos y siembras para una auto sostenibilidad, al igual se salen de las fronteras del colegio en busca de la protección del agua y la naturaleza, asumiendo retos de cuidado y regeneración de bosques, creación de reservas ambientales, planes de manejo, protección del terreno de la cría del ganado 
con cercas eléctricas, con ganadería responsable, biodigestores desde la creación de semilleros hasta la plantación de franjas de reservas de bosques.

En su relato, Hilda R. también destaca cómo la escuela ha logrado trabajar con los campesinos la importancia de la protección y el cuidado del medio ambiente, a tal punto que,

algunos de ellos han aceptado donar un espacio de 6 metros a lo largo de las fincas para la siembra de esta capa vegetal, que a la larga los beneficia con la frescura que proporcionan los árboles, la sombra para el ganado, el mantenimiento del agua para el mismo uso familiar, de siembra y cuido de ganado y otros animales.

Y adelantar, además, acciones para la recuperación de las especies en peligro de extinción. Tienen interés "por la preservación de especies de árboles como el bongo negro que se encuentra en vía de extinción como lo cuentan en el estudio que han realizado, al igual de especies de pájaros endémicas de esta hermosa región".

Esta es una práctica pedagógica estrechamente conectada con la propuesta de reconstrucción de territorio:

(...) los profesores se apoyan, se dan ideas y construyen talleres y organizan un currículo entretejido con los diferentes saberes, si tienen 7 estudiantes distribuidos en cada grado, buscan mediante un ejercicio o la lectura de un libro involucrar desde la suma, multiplicación, ángulos, desde la matemática, el español, la ortografía, biología, ecología, el dibujo y demás, la facilidad de involucrar el conocimiento con la práctica, direccionando mucha de su atención con el amor y cuidado del medio ambiente. (Hilda R.).

Los maestros asumen con orgullo su papel, reconociendo que, pese a todas las dificultades que se presentan, "se puede trabajar, se puede enseñar y enseñarles a los jóvenes a soñar con un futuro mejor", palabras de un profesor de grado segundo que recoge en su relato Hilda R. La perspectiva pasa por el territorio local, pero es mucho más amplio entrelazarse con otros que trabajan el tema ambiental para construir conjuntamente el territorio en Colombia y desde este la preservación de nuestro gran hogar la tierra.
Y en medio de toda esta apuesta educativa sobresale, según dice Carmen Alicia:

la capacidad de tomar en sus manos la educación que los mantiene en el tercer puesto en resultados de pruebas saber a nivel rural y el papel destacado de la mujer por ser ellas las que acompañan cada rincón con su esperanza.

Una escuela producto de las luchas del pueblo nasa del Valle del Cauca para preservar su cultura y la naturaleza y resistir el reclutamiento de sus hijos para la guerra: el Colegio IDEBIC, "El Gran Sueño de Ios Indios" (Florida, Valle del Cauca)

Hay que estar allí para escuchar desde la voz del mismo rector, Aníbal Bubú, la historia de esta propuesta educativa, orientada por los mayores de la comunidad Nasa del Valle del Cauca, preocupados por el reclutamiento de sus hijos para la guerra, así como por el auge de la coca, con sus efectos devastadores en la deforestación de sus montañas y en su cultura propia. "El Gran Sueño de los Indios", como se denomina en lengua propia el Colegio IDEBIC, es fruto de una larga lucha de la comunidad, de su capacidad para enfrentar las burocracias educativas y gubernamentales, que se han mostrado incapaces de entender la importancia que tiene la educación para estos pueblos:

Las comunidades indígenas deben luchar contra las entidades gubernamentales para conseguir el terreno y la aprobación del colegio. En esta construcción participa toda la comunidad, inclusive solicitan ideas de los ancianos (...), para ellos en el mundo indígena todo es posible si se trabaja en Unidad. (Rocío)

El rector es un líder indiscutible y tiene un amplio reconocimiento entre la población:

Ha luchado contra entidades por el territorio, su vida ha estado amenazada, parcelaron la tierra, (...) hoy tiene el reconocimiento a nivel local, nacional e internacional, trabajo que no es solo de él sino de la comunidad Nasa, como él mismo lo hace notar en sus presentaciones. (Ma. Esperanza)26

26 María Esperanza Ortiz, viajera, Colegio Quiba Alta. 
Su liderazgo no se puede entender sin esa conexión entrañable con sus mayores y con su pueblo, y con ese principio de la unidad, tan difícil de traducir y de hacer entendible, porque hace parte de ese vivir en comunidad. "Es parecido a eso que ustedes Ilaman trabajar en equipo o colaboración, pero no es lo mismo ...", nos dice el Rector; un aspecto que destaca Norma al sorprenderse con "ese Nosotros que usted reconoce en todo momento al hablar" y con el "trabajo colectivo y la autonomía con la que actúan". (Norma)27

Los cuatro principios de la comunidad — La unidad, la tierra, la cultura y la autonomía — orientan, a su vez, el Proyecto Educativo Comunitario (PEC), pues "permitirán la reivindicación y pervivencia de los pueblos indígenas en una estrecha relación armónica y equilibrada entre hombre y madre tierra, en el marco de los planes de vida" 28. Es con esta perspectiva como la malla curricular "Educando desde los planes de vida de los pueblos indígenas" define sus "componentes": Educación, Territorio, Jurisdicción, Salud, Economía y Espiritualidad, y, para cada uno de ellos, las respectivas áreas y asignaturas, para así dejar claro que interactúan desde los contenidos de la cultura propia, con otros contenidos y saberes de occidente, en una clara postura decolonial:

(...) a través de los años han luchado constantemente para sobrevivir a los azotes de una conquista, [al] auge del comercio de drogas y del conflicto armado, obligándolos a construir una estrategia basada en mantener su identidad, apoyándose en los Mayores y sus conocimientos, quienes demuestran con sus aportes y peticiones, que con la educación se transforman vidas, se forma en valores y se anclan a un lugar para seguir luchando para mantener sus costumbres. (Norma)

Las actividades escolares se inician en febrero, con la "autoridad escolar", cuando eligen al gobernante. Este es quien posee la sabiduría propia de su edad para liderar y gobernar en comunidad, y quien representará al colegio ante cualquier entidad. Los tiempos de la siembra, de las cosechas y de los ritos tradicionales definen el calendario escolar; “(...) el calendario ecológico en el que se rescatan las tradiciones y las temporadas de trabajo" (Norma).

27 Norma Constanza Moreno, viajera Colegio Jaime Garzón/San José Sur.

28 Fragmento del mural de la escuela donde se expone la Visión del Proyecto Educativo Comunitario.
Para situar los alcances del colegio, es importante tomar en cuenta que atiende, a su vez, las escuelas de 23 municipios de la región. Muchos de los estudiantes vienen de sitios lejanos, de "3 a 5 horas de camino, por lo cual el colegio ofrece el internado para dichos estudiantes" (Rocío).

Los proyectos pedagógicos tienen como referentes sus grandes ritos, a los cuales se refieren varios viajeros en sus relatos. María Esperanza los presenta de forma detallada:

- En marzo "la apagada del fuego "para amarrar los espíritus malos: se trata de apagar todos los fogones de las casas de la comunidad y encender una única hoguera en el colegio, así los espíritus malos que se encierran en el fuego lleguen a la hoguera y serán encerrados durante un año (...) ¡Hay que estar ahí para creerlo!

- El primero de mayo: "día de la tierra y el maíz", comparten alimentos a base de maíz (...).

- En junio (...) "el nacimiento del Sol" se trata de hacer un recorrido hasta el cerro y esperar a que alumbre el sol, exponer las manos y permitir que la energía del sol llene el cuerpo a través de las manos.

- En agosto es "la Danza de la Serpiente Verde" (...) la dueña del agua y se danza para que en los meses venideros haya agua suficiente y mantener los suelos fértiles (alimentar a la Pacha Mama).

- En noviembre conmemoran y festejan por los espíritus de los mayores (abuelos) que dejaron su cuerpo, pero que los acompañan "Cxapuc" (...) ritual que se hace a los que ya partieron invocando el acompañamiento y la buena salud de los familiares para que les guarde todo el año saludables sin enfermedades en el cuerpo ni en el espíritu.

Son numerosos los proyectos relacionados con el cuidado de la naturaleza y la producción agrícola y pecuaria, estrechamente vinculados a la malla curricular. Sorprendieron especialmente el sendero ecológico y los proyectos productivos; estos últimos, de gran envergadura en el sentido productivo, pero orientados, 
en primer lugar, a la alimentación de los estudiantes. En el relato de Rocío se especifican:

- La producción de abono orgánico, con desechos de la siembra de huerta, del restaurante, el estiércol de los animales, (...) produciendo toneladas de abono, ha sido la base para preparar los terrenos e iniciar los proyectos de café y banano. El abono también es utilizado para la huerta, los frutales y diversos cultivos...

- Se tienen trece mil plantas de café. El café recolectado es vendido a supermercados de Florida. El colegio tiene su propio beneficiadero, con personal diferente a estudiantes que está a cargo de este trabajo. En el momento se adquirió el laboratorio para procesar el café y sacar su propia marca.

- Proceso de producción de banano con abonos orgánicos producidos en el colegio; este alimento es utilizado para suplir la alimentación de los estudiantes del colegio y parte de las comunidades.

- Siembra de caña de azúcar y producción de panela, es vendida a los supermercados de Florida.

- Otros proyectos son: porcicultura, piscicultura. Con la porcicultura se fabrica un biodigestor, que produce energía para la cocina del colegio. La piscicultura es solo para la alimentación de estudiantes del colegio.

Para llevar a cabo toda esa propuesta, se requiere partir "desde las pequeñas cosas", en palabras del Rector, y se van haciendo realidad, "como el sendero ecológico diseñado y hecho realidad por ellos mismos que muestra un exquisito sentido de belleza y atracción y a la vez demuestra la forma en que se proyectan hacia los demás como comunidad", dice Norma. Al respecto, Rocío muestra cómo se integran en este proyecto los estudiantes y las comunidades:

ya se tiene adelantado, en algunas jornadas con estudiantes y sus familias han abierto camino entre el bosque que está aledaño a su colegio y dentro de la jornada escolar los estudiantes se encargan de reconocer la vegetación del bosque y van marcando los árboles con los nombres comunes en esa región...:
Una historia de 18 años que hoy por hoy muestra su valor incalculable con resultados tangibles como lo son el crecimiento del colegio, sus cultivos, la posición del colegio en las pruebas externas y la constitución de una dinámica propia en la que se tienen en cuenta las actividades de la comunidad y de la institución unificándolas. (Norma)

Una escuela capaz de reinventarse para que los estudiantes no se sientan obligados a estar en ella: el Colegio José Acevedo y Gómez (Medellín, Antioquia) (...) para mí se generó un punto de quiebre, fue una grata sorpresa, ver una forma particular y llamativa de enfocar el proceso formativo de los estudiantes, dando relevancia a un aspecto que como sociedad hemos descuidado, la autonomía, pero claro, no producto de un acto espontáneo, sino como el resultado de un proceso en donde el individuo se hace consiente de sus posibilidades y reconoce las de los demás, algo que en un contexto, rodeado por el micro tráfico, la prostitución y todo tipo de manifestaciones delictivas, se torna bastante complejo, en la medida en que los estudiantes ven pocas opciones de proyecto de vida y tienden a ignorar sus capacidades... (Sergio A)

Para entender la propuesta, es necesario ubicarla en el territorio específico donde se encuentran las cuatro sedes y evidenciar las múltiples rupturas que han hecho respecto a los supuestos de la organización y de la cultura escolar predominante, en la presentación que hace Irwin en su escrito:

Según la descripción dada por el director, señor Jaime Alberto Sierra, están ubicados en una zona de mediana complejidad entre Medellín e Itagüí, de tradición conservadora, zona con presencia de bandas delincuenciales (...), se podría decir que allí la violencia se vive de otra manera, tal vez menos compleja si se compara con otros lugares del Valle del Aburra, un ejemplo de ello, dice el director, es que las fronteras invisibles no son tan marcadas como en otros lugares, no se da el caso que un estudiante no pueda llegar al colegio por evitar cruzar una de estas fronteras. Las bandas que hacen presencia en el sector reconocen a la institución como un lugar en el que pueden dejar de lado sus diferencias. ${ }^{29}$

29 Irwin Medina, maestro viajero IPN. 
Sorprenden el atrevimiento y la decisión de su rector, Jaime Sierra, y de cada uno de los maestros que en esta escuela han conseguido hacer unas rupturas tan marcadas respecto a la cultura escolar convencional y predominante. Es otro modo de pensar la "inclusión", que pasa por entender la complejidad de las condiciones en las que han vivido los niños y los jóvenes que habitan este territorio y han tenido experiencias negativas en otras escuelas:

Se dijo antes que la política de la institución es la inclusión escolar, se recibe en cualquier momento del año a toda persona -sin importar su edad-que desee educarse; ya una dificultad manifiesta es que a la institución lleguen estudiantes que han sido tradicionalmente maltratados en otras escuelas y por tanto la posibilidad que deserten es alta, así que con diferentes tácticas, la institución intenta mantener a los estudiantes interesados por permanecer en ella, muestra de ello es que hace 20 años erradicaron la obligatoriedad del uso de un uniforme, se autoproclaman escuela de puertas abiertas, en el sentido literal atienden población de domingo a domingo, han sido líderes en la formación docente por medio de alianzas con universidades capacitando a los maestros en derechos humanos, hacen a los estudiantes autónomos en su formación y evaluación, entre otras cosas. (Irwin)

En un interesante juego entre la confianza y la exigencia, que se expresa en diferentes aspectos de la vida escolar cuyo proyecto educativo se centra en la autonomía, la confianza y la ciencia. La apuesta es contundente:

Es un compromiso de la institución hacer que los estudiantes se mantengan dentro del sistema educativo, evitar al máximo la deserción escolar. Para esto se apoyan en la idea que al estudiante debe gustarle estar en la escuela, el estudiante no debe sentirse obligado a estar en la escuela, debe gustarle tanto que quiera permanecer en ella, de tal forma de pensar se desprende que el aspecto académico (...) pierde importancia y lo importante es que el estudiante reflexione sobre el cambio que la escuela puede producir en su propia vida. (Irwin)
¿Darle más importancia a la incidencia de la propuesta sobre la propia vida? Algunos dirían que esto no le corresponde a la escuela... ¿Acaso no se privilegian los "aprendizajes" y los resultados estandarizados de las escuelas, independientemente de quiénes son sus estudiantes, sus historias y sus vidas?

A continuación, se presentan fragmentos de los textos que muestran cuáles son las rupturas que destacan los viajeros y el modo como las entretejen con sus propias reflexiones acerca de la vida escolar, el papel del maestro, sus relaciones con los estudiantes y sus propias prácticas:

- Las normas, el uniforme y el reconocimiento de la diversidad

(...) una breve charla, que igual bien pudieron haber obviado, ya que su filosofía, sus formas de enseñar y su compromiso con la rigurosidad científica (en todos los aspectos) saltan a la vista; aquí de nuevo el asunto trivial de la estética, el uniforme, los estilos, etc.... no está siquiera en discusión, los estudiantes corren libres por las instalaciones portando las prendas y accesorios que les parecen más cómodos, me es inevitable pensar que entre más importancia se le da al hecho de uniformar, rotular, restringir, censurar, más desviamos el proceso formativo de cuestiones realmente importantes...¿Cómo hablar de diversidad si pretendemos verlos a todos iguales? ¿Cómo promover la tolerancia y el respeto si limitamos la libertad de expresión? (Sergio)

Así mismo, Sergio destaca los distintos planos en los que se mueve una escuela y resalta la importancia de las relaciones que establecen los maestros con sus estudiantes, al referirse a una escuela que

deja en un segundo plano cuestiones que cuando se tienen en cuenta solo generan tensión en la relación estudiante profesor, en donde este último termina asumiendo un papel casi que policivo, lo que solo termina por distanciarlos dificultando muchos procesos formativos, aniquilando gradualmente la confianza que sobre el docente pueden tener los estudiantes. 
- La evaluación

La forma de evaluar en la institución educativa es bastante impactante, puesto que esta gira en torno a la autoevaluación, reforzando la idea de autonomía, que es uno de los principios institucionales -los otros son solidaridad y ciencia-, la evaluación deja en manos del estudiante la reflexión de su proceso de aprendizaje y la valoración de su evaluación que es guiada por los criterios evaluativos de cada asignatura propuestos por el docente. Es tan serio el proceso que en ocasiones los estudiantes repiten año, cabe resaltar que el porcentaje de pérdida de $0.4 \%$ registrado los últimos años, aunque es bajo, las directivas piensan en cómo reducirlo. (Irwin)

Al respecto, Marcia Alejandra recoge las palabras de un maestro de segundo grado de esta escuela, en las cuales se expresa el carácter autónomo y responsable que tienen los estudiantes con su evaluación, y que es lo que los maestros se han propuesto: "... cuando un niño o niña me habla y dice "yo merezco", tengo la seguridad de haber logrado un cambio ...".

Sergio resalta las relaciones entre la evaluación y el énfasis en la formación en ciencias:

llegando a un punto en donde son capaces de asignarse una nota (en la mayoría de los casos) justa y coherente con el proceso académico que han llevado, todo en el marco de la solidaridad y la motivación por el trabajo científico.

- La convivencia y las problemáticas propias del entorno

Llama la atención que, si bien el colegio cuenta con un manual de convivencia, dado que es una obligación para todo colegio, universidad o institución educativa no formal, en este caso se privilegian la confianza y la autonomía, que son los principios orientadores de la propuesta educativa. “(...) En relación con la convivencia, reconocen que tienen manual de convivencia porque es una obligación, pero resaltan que la manera en que la manejan es diferente a lo habitual, pues prefieren utilizar el diálogo con el estudiante", como lo cuenta Irwin.
Por otra parte, la escuela está atenta a identificar las problemáticas que atraviesan el entorno de vida de sus niños y sus jóvenes, como en el caso de la prostitución y de los embarazos tempranos:

Existen otras dificultades de convivencia escolar derivadas del entorno, por ejemplo, el alto índice de embarazo en adolescentes, para disminuirlos han diseñado una cátedra llamada psico-sexualidad desde la cual hacen esfuerzos para educar a las niñas en temas sexuales, reproductivos y afectivos. (Irwin)

- La formación científica

En este ambiente de trabajo y con las estrategias implementadas —según recalca Sergio_-, es notorio cómo se favorece la formación de personas críticas, reflexivas, autónomas, conscientes de la importancia de estudiar y comprender su entorno, en procura de comprenderlo mejor y así poderlo proteger con más argumentos y audacia:

Fue realmente grato ver a estudiantes apropiados completamente de los temas de estudio, tomando datos meteorológicos con gran habilidad (datos que pueden o no tomar, no están obligados a hacerlo), como una simple labor más de su cotidianidad, para luego tenerlos en frente enseñándonos a procesar tan valiosa información, siempre de una forma reflexiva y con una visión global de las circunstancias, completamente sorprendidos por la cantidad de agua que puede caer en una pocas horas de lluvia, y pensando en aquellos lugares donde muchas personas sufren por la carencia del preciado líquido. (Sergio)

El cuento con los cuentos infantiles (Alfredo Cock Arango, Medellín)

La práctica que adelanta Nora Villa con los niños y niñas del grado de "Transición", en una de las zonas de Medellín marcadas por las "fronteras invisibles", ha permitido ver que en este país hay maestras y maestros que se atreven a ensayar y a inventar, que existen pedagogías producto de una sensibilidad exquisita para aproximarse a los niños y niñas, para trabajar con ellos los sentimientos de soledad, los miedos y la desconfianza que producen esos entornos de pobreza, de desarraigo y de múltiples violencias en los que se ven obligados a crecer. 
Ahora sabemos que los cuentos son sanadores y pueden ser una terapia para el alma, que existen maestras que, en vez de ignorarlas, problematizan estas duras realidades desde las preguntas propias de la pedagogía. Y también, que, con este modo de construir y pensar una pedagogía, que podríamos Ilamar "de la esperanza", hay maestras como Nora, que desafían la imaginación haciendo cómplices a miles de personajes sacados de los cuentos, para que los niños y las niñas no estén solos, para invitarlos a la escritura por medio de "dibujos, sonrisas y garabatos", para romper con las "ataduras emocionales", para construir la confianza en sí mismos y en la vida. Indudablemente, todo esto requiere ser visibilizado, porque se convierte en una importante contribución al pensamiento sobre la pedagogía, a la formación de maestros y a la construcción de unas políticas educativas que tengan en cuenta los aportes de maestros que viven, problematizan y actúan frente a estas problemáticas, como lo expresa Sonia:

Debido a la mirada administrativa sobre la escuela, algunas veces se suele caer en las tres palabras que miden la escuela: la eficiencia, la eficacia y la efectividad en el marco de pruebas estandarizadas que comparan y discriminan las instituciones educativas en una pelea, incluso entre jornadas por demostrar cuál es mejor, desconociendo el papel real de la educación, los contextos y dejando por fuera los procesos que algunos maestros pilos deciden asumir a costa y riesgo propio.

También tiene presencia en este colegio la propuesta de las "Bibliotecas Ambulantes", de Duvan Gil. Este bibliotecólogo da vida a una propuesta en la cual la biblioteca no es solo un escenario para la realización de interesantes actividades de lectura y cine: además, sale del encerramiento, va al aula, se involucra en la construcción conjunta de propuestas en las que los estudiantes y los maestros encuentran espacios para la investigación en diferentes campos y para el fortalecimiento del proyecto de lectura, escritura y oralidad de la institución.

El "ánimo sanador" no solo se ha contagiado ya a otros maestros y funcionarios del Alfredo Cock Arango, sino que también se ha extendido a las maestras visitantes, como se puede ver en los siguientes fragmentos de las cartas y los relatos viajeros: un viaje que nos permite volver a recordar por qué elegimos un día convertirnos en maestros, por qué persistimos en repensar nuestras prácticas y buscar un cambio a pesar que la sociedad desestime nuestra labor 30 ; se han convertido en la esperanza de aquellos que sin saberlo no deberíamos nunca dejar de ser niños, fueron como medicina para aquellos que aún queremos seguir siéndolo, para escuchar y encontrar consuelo en cada cuento narrado por personas tan entregadas como ustedes y así nunca dejar de soñar. 31

Vemos así, en los relatos de los viajeros, otros lenguajes. Lenguajes muy diferentes de los imaginarios y de los discursos de las políticas hegemónicas, que pretenden responsabilizar al maestro de las deficiencias de la denominada "calidad" de la educación, en las perspectivas diagnósticas, de la evaluación, de los resultados de "aprendizaje". Y aun cuando inicialmente algunos supusieron que llevarían sus trabajos a modo de "modelos" para enseñarles a otros cómo se hacen "buenas" o "mejores" prácticas, estas narrativas dejan ver unas relaciones distintas, entre pares, de doble vía, intercambios que podemos llamar "en red", que producen admiración y generan nuevas preguntas, posibilidades de pensarse y de actuar distinto, sin fórmulas, sin respuestas. A eso se refiere Sergio en su relato:

(...) tuvimos la posibilidad de exponer de forma breve nuestro proyecto, que fue muy bien recibido, y de escuchar interesantes experiencias desarrolladas en contextos poco favorables en términos de conflicto y recursos, lo que pone de manifiesto el valor real de la educación, cuando esta se encuentra en manos de docentes comprometidos con su causa, convencidos del cambio social que pueden generar desde su quehacer y que enriquecen su labor desde la creatividad y entereza.

Dice María Cristina: “(...) poder compartir en doble dirección estas experiencias [...] quizás seguramente se constituye en un modo dinámico y contextual para recuperar el estatus de la pedagogía como un saber propio".

\footnotetext{
30 Ingrid Rubio, Nelson Velosa y Dalila Castillo, viajeros IPN

31 Nelson Velosa y Dalila Castillo, viajeros IPN, carta a maestra anfitriona Alfredo Cock Arango.
} 
Los cambios que produce la "experiencia", en las palabras de los participantes

En la experiencia de los viajes, tal como esta es contada por los maestros, muchas cosas quedan atrás. Se abren mundos diferentes, ya no pueden ser los mismos. ¿En qué consisten esos cambios?

La intensidad de la experiencia del viaje en forma de nuevos interrogantes, aperturas e ideas se deja ver en el siguiente relato de Sonia:

Es una reflexión que interroga mi trabajo y que grita al oído "A mí no se me hubiera ocurrido" o además de esto que estoy viendo y viviendo también podría hacer esto o aquello y se generan en nuestra mente una serie de ideas que renuevan el ropaje viejo al que uno se acostumbra cuando no sale de las cuatro paredes del aula y devela otras rutas posibles.

Carmen A. y Carolay nos hablan de una nueva manera de ver los territorios en los que trabajan y sobre la confianza en su propio poder como maestras, al reconocer los cambios producidos por otros en los lugares visitados:

Caminar mi amada Ciudad Bolívar, después del Dovio es una invitación diaria a buscar entre las calles desordenadas y hacinadas, la diversidad, la multiculturalidad, los paisajes escondidos...es reflexionar sobre mi responsabilidad como docente de ser parte de la construcción de un territorio, que nos es ajeno a todos pero que nos abriga y sostiene. Es entender, que mi labor puede ser parte del cambio y que las metas, aunque estén lejos se pueden cumplir. Es tener la certeza que la persistencia y el amor son el mejor ejemplo y es la tranquilidad que en algún lugar de Colombia la vida ya empezó a cambiar. (Carmen A.)

Inspiración es lo que los indígenas Nasa han producido en mi interior, una inspiración que se está nutriendo de las ansias de mejoramiento de mi territorio, de mi nicho, de mí ser; hoy soy otra persona, una que cree en sí misma y en lo que su comunidad puede lograr con pertenencia y dedicación. (Carolay)
Carolay cuenta cómo su vida profesional y personal se ha visto "sacudida" ante las posibilidades que se abren cuando se constata que los cambios sí son posibles:

(...) un día que sacudiría mi vida profesional e indudablemente la persona (...) Partir de creer que el cambio es posible y que el trabajo en equipo es la base para la construcción de sociedad es la enseñanza más grande que me dejó el diálogo con el profesor Aníbal, supe que el camino que estaba recorriendo era el correcto, que soñar era una opción y que amar lo que se hace permite mejorar y alcanzar nuestras metas.

Pablo lo expresa de la siguiente manera:

La experiencia de los maestros viajeros es inigualable, ya que nos genera procesos de pensamiento diversos y experiencias de vida que nos hacen cuestionarnos frente a nuestra cotidianidad y nuestra labor docente. Es ver la educación, la enseñanza y el aula desde una óptica muy diferente. 32

Marcia revela cómo las "palabras y experiencias" vividas durante el viaje fortalecen su labor de enseñanza y la Ilevan a valorar su colegio como nunca lo había hecho:

Hoy, después de tres semanas, y de nuevo autoevaluándome, puedo decir: en el universo me identifico en un rol con la sociedad en la cual me desenvuelvo; ocupo una pequeña parte de Bogotá, en un rol con los niños y niñas que están a mi alrededor. Ocupo un espacio del Instituto Pedagógico Nacional, un colegio al que en el transcurso de tres días aprendí a valorar más de lo que lo había hecho en los tantos años que llevo allí. Ocupo una muy pero muy pequeña parte del universo, pero lo suficientemente grande para que muchas de las palabras y experiencias que marcaron el corazón y la mente, fortalezcan mi labor y permitan difundir mi sentir de la mejor manera: enseñando.

Luz Dary también se refiere a este asunto: "He logrado reflexionar mucho más sobre mis prácticas pedagógicas; la esencia de mi profesión, la razón por la cual decidí estudiar esta carrera y sobre la vida misma ...33

32 Pablo Daniel Reyes, viajero Colegio José Javier Matiz.

33 Luz Dary Granados, viajera IPN. 
Pero es, quizá, el tema de la construcción de lo colectivo y la ruptura con el individualismo lo que más ha impactado a los maestros en estos viajes, como lo expresan numerosos relatos:

Otra idea que fortifiqué después de escuchar la experiencia IDEBIC fue la de cimentar y reforzar la identidad como pueblo, como grupo y como comunidad, que el reconocerse como agente de un lugar genera pertenencia, amor propio y mentalidad compartida, hace que queden atrás las ideas individualistas y abre paso al trabajo común y a los relatos de surgimiento y visibilización de lo que somos y podemos llegar a ser. (Carolay)

La escuela expedicionaria potencia sentidos y saberes en colectivo, aspectos que nos motivan a seguir en la transformación de nuestras prácticas educativas. (Nelcy, Blanca y Jenny)

(...) ha generado en mí un nuevo sentir sobre la educación, en el que el trabajo en equipo da mayores resultados que el trabajo hecho individualmente. Aspecto que debo empezar a corregir. Debo apoyarme en mis compañeros, aunque este sea un colegio urbano existen posibilidades. (Norma).

Las características de algunas de las prácticas visitadas tienen unos impactos específicos, cambian los modos de pensar sobre determinados temas. Es el caso del colegio José Acevedo y Gómez, de Medellín, que lo hace en lo relacionado con los modos de pensar las prácticas y la cultura escolar, en lo que tiene que ver con la construcción de la autonomía. Así lo expresa Irwin:

(...) de la experiencia que ellos tienen se puede aprender para buscar que los estudiantes del IPN realicen una mejor autoevaluación y que esta sea fruto de un proceso de reflexión alejado del afán de una asignación de nota ... Es importante reconocer los esfuerzos realizados por otros maestros y reconocer en estos una herramienta para autoevaluar la labor docente que realizamos.

Sergio, María Cristina e Irwin lo expresan de la siguiente manera:
Todo esto se tornó para mí como una invitación abierta a buscar estrategias desde mi quehacer diario para fortalecer la autonomía entre mis estudiantes, de la mano con la solidaridad, ya que siempre he promovido y reivindicado la rigurosidad, especialmente, en cuanto a ciencia se refiere. (Sergio)

Reconocer que existen diversidad de prácticas y el modo como estas se relacionan con los lugares produce en algunos viajeros otra manera de pensar la escuela y con ello sus propias prácticas: "poder entender que el maestro tiene un saber y una práctica, y que la formación debe estar conectada con sus prácticas, diferentes entornos económicos, sociales, políticos y pedagógicos. (María Cristina)

Es importante reconocer a este colegio y otros como una manera distinta y valida de hacer escuela, las formas, porque no es una, de hacer escuela nunca debe estar alejada de su realidad social, del entorno físico, y del entorno familiar de los escolares, hecho que hace pensar en que es un error importar procesos y formas de hacer escuela de otros países o de otras regiones en las que posiblemente la forma de hacer escuela sea exitosa por que responden a un entorno, diferente al de otros lugares y al de otros colegios. (Irwin)

La siguiente cita de Carmen A. permite ver las dimensiones de estos viajes en términos del reconocimiento de la Colombia profunda, con su biodiversidad, sus poblaciones distintas, las huellas profundas de la violencia, de la pobreza y de las circunstancias específicas de las poblaciones; un asunto central que replantea y amplía la mirada que tiene el maestro de sí mismo y de las dimensiones de su quehacer más allá de la escuela en la que trabaja, como sujeto político, como ciudadano del mundo:

La diversidad de Colombia es un fenómeno difícil de imaginar y dimensionar, desde la vivencia homogénea y plana de la ciudad. Qué difícil es entender lo que implica pasar de $36^{\circ} \mathrm{C}$ a un frio bosque de niebla en el lapso de 10 minutos, lo que significa en términos económicos y producti- 
vos habitar una tierra donde haya más de un piso térmico, caminar entre selvas húmedas, bosques secos y cálidos en una sola tarde... pero además, entender cómo cada uno de estos paisajes están dibujados a través de indígenas, colonos, campesinos y diversos habitantes que hacen aún más profunda su particularidad; hombres, mujeres, jóvenes y niñ@s que se empeñan cada día en vivir un territorio que otrora se manchó de sangre, ilegalidad, miedo, inequidad y ruptura moral, pero hoy luego del conflicto florecen las semillas que a través de los intersticios respiraron durante mucho tiempo un nuevo territorio.

Y ahondando sobre las implicaciones de los viajes en las relaciones entre maestro, pedagogía y política, afirma Claudia:

(...) invitan a un trabajo constante por reivindicar la riqueza que se encuentra en la escuela del sector público (...) pero, para mí su mayor riqueza son las distintas apuestas, los sueños e ilusiones que tejen a diario las maestras y maestros, la manera como desde nuestro oficio vamos construyendo escuela, vamos transformándola, en la medida que el trabajo se articula en torno a la enunciación de otras maneras de vivir el país que se alejan de la violencia, la generación de nuevas territorialidades que nos permitan entender lo local y nacional como propios, la configuración de subjetividades que entiendan sus posibilidades de transformar las realidades de nuestro país. La escuela se convierte en un lugar de resistencia ante todo el sufrimiento que ha vivido este país y es un lugar de reformulación de un proyecto de nación que incluya a la mayoría y que reconozca en todos el carácter de ciudadanos. 34

\section{Referencias}

Echeverry, A. (2009). Campo conceptual de la Pedagogía: una contribución. Tesis de Doctorado en Educación, Universidad del Valle.

Expedición Pedagógica Nacional (2001). Preparando el Equipaje. Caja de Herramientas. Bogotá: Universidad Pedagógica Nacional.

Expedición Pedagógica Nacional (2001). Huellas y Registros. Bogotá: Universidad Pedagógica Nacional.

Federicci, C., Mockus, A., Charum, J., Granés, J., Castro, M., Guerrero, B. \& Hernández, C. (1984). Límites del cientificismo en educación. Revista Colombiana de Educación, 14, 69-90.

González, F. (1929). Viaje a pie. Medellín: Bedout, $3^{a}$ edición.

Jay, M. (2003). La crisis de la experiencia en la era postsubjetiva, Chile: Universidad Diego Portales.

"La Maldición del Cañón de Garrapatas" (2014, 1 de septiembre). Cali: El País. Recuperado el 16 de noviembre de 2014 de: http://historico.elpais.com.co/paisonline/notas/Agosto072005/ C607N1.html

Martínez, A. \& Unda, M. (1995). Maestro: sujeto de saber y prácticas de cualificación. Revista Colombiana de Educación, 31, 93-107.

Messina, G. \& Quiceno, H. (2002). Expedición a la Expedición Pedagógica Nacional. Bogotá: UPN-Expedición Pedagógica, Fundación A. Restrepo Barco.

Quiceno, H. (2001). Viaje, Formación y Educación. En: Expedición Pedagógica Nacional, Pensando el Viaje (pp.63-76). Bogotá: Editora Guadalupe.

Rodríguez, A. (2002). El Movimiento Pedagógico: un encuentro de los maestros con la pedagogía. En H. Suárez (Ed.). Veinte años del Movimiento Pedagógico (pp. 15-60). Bogotá: Magisterio, Corporación Tercer Milenio.

Zuluaga, O. (1999). Pedagogía e Historia. La historicidad de la enseñanza, un objeto de saber. Bogotá: Anthropos.

34 Claudia María Vargas, viajera Colegio Guillermo Cano.

Temas de la red / Viajes y encuentros pedagógicos como 25 experiencias de formación de maestros / / María del Pilar Unda B / Alba Nelly Gutiérrez C. / 


\section{Diálogo del conocimiento}

\section{El viaje como formación}

Se cita a menudo la frase de Miguel de Unamuno, escritor español perteneciente a la 'Generación del 98', según la cual el fascismo se cura leyendo y el racismo viajando. Nada más cierto. Gracias a la lectura y al estudio podemos ampliar nuestros horizontes, nuestras miradas cerradas y auto referenciadas. El estudio de los libros, que en el fondo no es más que una forma diferente de viajar, nos lleva a otros mundos $y$, además, hace posible que seamos otros, que experimentemos nuevas perspectivas, que observemos desde otras situaciones y que reflexionemos tomando en cuenta otras condiciones. Así logramos romper los esquemas que nos amarran. De esa manera podemos derrumbar esas certezas que en apariencia nos llenan de seguridades, pero que en el fondo no son más que límites que ponemos a nuestras comprensiones. La lectura nos permite liberarnos de los prejuicios, de los estereotipos, subvertir el autoritarismo que llevamos por dentro en mayor medida de lo que en principio estamos dispuestos a reconocer.

Viajar es también un camino de formación. Al entrar en contacto con otros lugares, al experimentar diferentes contextos, al explorar nuevos territorios y al entrar en contacto con personas diferentes se abren las mentalidades y cesan las formas de exclusión y de discriminación. Viajar implica abrir los corazones y dejar de estar preso de los propios miedos, permite liberarnos del etnocentrismo y de la xenofobia. Al viajar aprendemos a valorar al otro, comprendemos que la diferencia no es obstáculo, no constituye una dificultad que debemos superar y extirpar. Viajar nos aleja de la tentación de la homogeneidad y de la aspiración a la uniformidad, nos libera del racismo.

Viajando encontramos que las diferencias culturales vinculadas a los contextos no solo nos diferencian y generan distancias, también nos unen. Es como si viajar fuera una manera de acercarnos, de descubrir que se puede construir desde la diversidad, pues al fin y al cabo los otros enfrentan retos similares, comparten sueños semejantes, tienen aspiraciones comunes. Somos humanos, demasiado humanos. Es en ese reconocimiento de las diferencias, pero también en el descubrimiento de lo que es común, que viajar se muestra como una opción formativa, pues se desencadenan propósitos compartidos, se experimentan innovadoras formas, se descubren respuestas y miradas novedosas. En el viaje se transforma el viajero, por supuesto, pero también el anfitrión se modifica, se enriquece, se tensiona y encuentra en las preguntas de sus visitantes nuevas respuestas a sus formas de actuar en el mundo y de valorar los pensamientos.

Tal vez es ese poder formativo el que hace posible que en el texto Viajes y Encuentros Pedagógicos como experiencias de formación de maestros -que los lectores encuentran a continuación- se puedan leer tantos y tantos testimonios de ese poder formativo y de esa capacidad de innovación que tienen los encuentros y los viajes para el ejercicio de la profesión docente. Las y los invito a que viajen por este documento con espíritu de explorador, con el convencimiento de que solo podemos transformar la formación docente cuando nos arriesgamos a prácticas creativas y a concepciones alternativas.

Rafael Pabón García 